\title{
Re: Calvarial Tuberculosis in a Preschool-Aged Child An uncommon entity
}

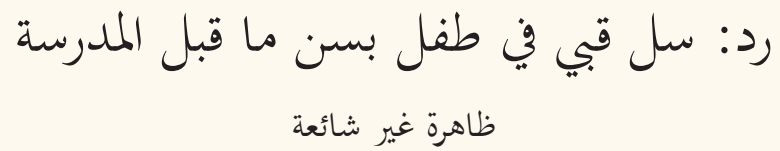

Sir,

I read with interest the case report by Santra et al. published in the November 2017 issue of SQUMJ in which the clinical presentation and management plan of a two-and-a-half-year-old Indian child with calvarial tuberculosis (TB) was described. ${ }^{1}$ It is possible that an HIV infection could have contributed to such a rare case of paediatric calvarial TB. As a result of the development of more potent antitubercular drugs and improved socioeconomic standards, there has been a remarkable reduction in the number of TB cases worldwide; however, atypical and extrapulmonary TB cases among HIV/AIDs patients nevertheless represent a major proportion of new TB cases. ${ }^{2}$ In particular, HIV and TB remain distressing health hazards in India, with a substantial prevalence of co-infection (12.3\%); moreover, $56 \%$ of TB lesions among co-infected Indian patients are extrapulmonary. ${ }^{3}$ It has been recommended that all TB patients in India should be evaluated for HIV risk factors and counselled to undergo HIV testing, while all HIV-positive cases should be screened for TB. ${ }^{3}$

Although there are no recent data on the exact seroprevalence of paediatric HIV in India, the available literature indicates that the HIV seroprevalence rate among pregnant Indian women is $1.03 \%{ }^{4}$ According to Santra et al., the HIV status of the mother of the studied child was not determined; therefore, I presume that some sort of vertical HIV transmission could have occurred. ${ }^{1}$ A cluster of differentiation (CD)4 count and viral overload estimation should hence be undertaken. If this diagnostic battery of tests were to reveal an HIV infection, the case in question could be considered the second case of HIV-associated calvarial TB in India, following the first case reported by Tripathi et al. a decade ago. ${ }^{5}$ Regardless, the case is still novel in that it documents the youngest patient with calvarial TB reported in the literature to date. ${ }^{1}$

\author{
Mahmood D. Al-Mendalawi \\ Department of Paediatrics, Al-Kindy College of Medicine, University of Baghdad, Baghdad, Iraq \\ Author'se-mail:mdalmendalawi@yahoo.com
}

\section{References}

1. Santra A, Sen A, Chatterjee A. Calvarial tuberculosis in a preschool-aged child: An uncommon entity. Sultan Qaboos Univ Med J 2017; 17:e484-6. doi: 10.18295/squmj.2017.17.04.020.

2. Saleeb PG, Buchwald UK. [Update on the epidemiology, diagnosis and therapy of tuberculosis in HIV-infected patients]. Pneumologie 2014; 68:666-75. doi: 10.1055/s-0034-1377514.

3. Manjareeka M, Nanda S. Prevalence of HIV infection among tuberculosis patients in Eastern India. J Infect Public Health 2013; 6:358-62. doi: 10.1016/j.jiph.2013.04.004.

4. Sibia P, Mohi MK, Kumar A. Seroprevalence of human immunodeficiency virus among antenatal women in one of the institute of northern India. J Clin Diagn Res 2016; 10:QC08-9. doi: 10.7860/JCDR/2016/20615.8421.

5. Tripathi AK, Gupta N, Khanna M, Ahmad R, Tripathi P. Tuberculosis presenting as osteolytic soft tissue swellings of skull in HIV positive patient: A case report. Indian J Tuberc 2007; 54:193-5. 


\section{Response from the Authors}

Sir,

Thank you very much for your useful comments regarding our recently published case report. ${ }^{1}$ As you quite rightly mentioned, HIV and tuberculosis (TB) are serious concerns in India; in our experience, we very often come across cases of HIV-TB co-infections. As such, every TB patient should be screened for HIV as per the guidelines of the Revised National Tuberculosis Control Programme. ${ }^{2}$ The child in question was in fact tested for HIV and found to be negative; therefore, HIV was not considered to be a contributory factor to the development of TB in this case. ${ }^{1}$ In fact, this is why the child's mother was not tested for HIV. Unfortunately, we did not provide this important piece of information in the published case report. ${ }^{1}$ We are thankful to you for aptly pointing this out. Additionally, to the best of our knowledge, our case report documents the second youngest patient with calvarial TB. In a previous case series, Diyora et al. reported a one-year-old male child who presented with calvarial TB and was cured via surgical excision and a 12-month course of antitubercular therapy. ${ }^{3}$

"Avradip Santra, ${ }^{1}$ Arya Sen, ${ }^{2}$ Atri Chatterjee ${ }^{3}$

${ }^{1}$ Department of Pulmonary Medicine, Kolkata Medical College E Hospital, Kolkata, West Bengal, India; ${ }^{2}$ Department of Pathology, Murshidabad Medical College E Hospital, Murshidabad, West Bengal, India; ${ }^{3}$ Department of Neurology, AMRI Hospital, Kolkata, West Bengal, India

*Corresponding Author's e-mail: dravradip@gmail.com

\section{References}

1. Santra A, Sen A, Chatterjee A. Calvarial tuberculosis in a preschool-aged child: An uncommon entity. Sultan Qaboos Univ Med J 2017; 17:e484-6. doi: 10.18295/squmj.2017.17.04.020.

2. Kumar A, Gupta D, Nagaraja SB, Singh V, Sethi GR, Prasad J; Indian Academy of Pediatrics. Updated national guidelines for pediatric tuberculosis in India, 2012. Indian Pediatr 2013; 50:301-6. doi: 10.1007/s13312-013-0085-1.

3. Diyora B, Kumar R, Modgi R, Sharma A. Calvarial tuberculosis: A report of eleven patients. Neurol India 2009; 57:607-12. doi: 10.4103/00283886.57814 